\title{
The Impact of Core-Shell Nanotube Structures on Fracture in Ceramic Nanocomposites
}

\author{
Xin Liang ${ }^{1,2}$, Yingchao Yang ${ }^{3}$, Jun Lou ${ }^{3}$, and Brian W. Sheldon ${ }^{1 *}$ \\ ${ }^{1}$ School of Engineering, Brown University, Providence, RI 02912, USA \\ ${ }^{2}$ School of Materials Science and Engineering, Changzhou University, Changzhou, \\ Jiangsu 213164, China \\ ${ }^{3}$ Department of Materials Science and NanoEngineering, Rice University, \\ Houston, TX 77005, USA \\ Corresponding author: brian_sheldon@brown.edu
}

\begin{abstract}
Multi-wall carbon nanotubes (MWCNTs) can be used to create ceramic nanocomposites with improved fracture toughness. In the present work, atomic layer deposition (ALD) was employed to deposit thin oxide layers on MWCNTs. These core-shell structures were then used to create nanocomposites by using a polymer derived ceramic (PDC) to produce the matrix. Variations in both the initial MWCNT structure and the oxide layers led to substantial differences in fiber-pullout behavior. Single tube pullout tests also showed that the oxide coatings led to stronger bonding with the ceramic matrix. With high defect density MWCNTs, this led to shorter pull-out lengths which is consistent with the conventional understanding of fracture in ceramic matrix composites. However, with low defect density MWCNTs longer pullout lengths were observed with the oxide layers. To interpret the different trends that were observed, we believe that the ALD coatings should not be viewed simply as a means of altering the interfacial properties. Instead, the coated MWCNTs should be viewed as more complex core-shell fibers where both interface and internal properties can be controlled with the ALD layers.
\end{abstract}


Keywords: ceramics, composites, carbon nanotube, fracture 


\section{Introduction}

Conventional fiber reinforced ceramics exhibit substantially improved fracture toughness, due largely to crack bridging and energy dissipation associated with fiber pull-out ${ }^{[1-10]}$. Analogous approaches can be applied to nanoscale materials, where researchers have primarily tried to mimic these effects with carbon nanotubes (CNTS) which are roughly two orders of magnitude smaller than conventional carbon and ceramic fibers ${ }^{[11-15]}$. This reduction in size leads to important new questions - in particular, the extent to which the same toughening mechanisms are important at the nanoscale. For example, in brittle matrix composites reinforced by micron sized fibers, the energy consumed by pulling the embedded fibers out against residual frictional stresses at the interface with the matrix is often a major contribution to higher fracture toughness. However, it is not clear whether this type of pullout provides significant toughening in CNT reinforced ceramics ${ }^{[16-17]}$.

The research presented here employs atomic layer deposition (ALD) to create a broader class of CNT reinforced ceramics. This approach resembles interface coating strategies that are employed in conventional composites, where a variety of methods have been used to create coatings with thicknesses on the order of $100 \mathrm{~nm}$ or more, on fibers with diameters of several microns or larger ${ }^{[18,19]}$. ALD provides a well-controlled method for extending this type of interface engineering to CNT length scales. Analysis of conventional composites typically distinguishes bulk properties of the fiber (elastic constants, fracture strength, etc) from key interface properties (interfacial sliding resistance), where the latter can be effectively controlled with interface coatings. However, in ALD coated CNTs it is possible that the coating alters both the "bulk" properties of the reinforcement and the interface properties. Investigation of this possibility is a central motivation for the work reported here.

Our previous studies provide some initial information about ceramic matrix composites with functionalized CNTs ${ }^{[20]}$. In the present work, we selected two types of commercial multi-wall carbon nanotubes (MWCNTs) with very different defect levels and morphologies, and systematically coated them with $\mathrm{Al}_{2} \mathrm{O}_{3}$ and $\mathrm{HfO}_{2}$ using atomic 
layer deposition (ALD). These surface-modified MWCNTs were then infiltrated with a polymer derived ceramic (PDC) matrix to created ceramic nanocomposites. Fracture surfaces were carefully characterized and statistically analyzed, and single CNT pull-out tests were used to provide quantitative information about interfacial failure. The results show that the impact of the ALD coatings is strongly affected by the initial MWCNT structure.

\section{Experimental}

Two commercial MWCNTs were used in the present study. One type was obtained from Mitsui Corporation in Japan and the other was from Helix Material Solutions Inc. (Richardson, TX). Both materials exhibited a similar range of tube diameters, from $50-150 \mathrm{~nm}$. Carbon nanotubes grown in our lab by CVD (chemical vapor deposition) were also used for initial testing of the atomic layer deposition (ALD) parameters to confirm coating materials, and to observe surface morphology and determine the coating thickness - deposition cycle relationship.

Tetrahydrofuran (Ward Hill, MA) was used to uniformly disperse MWCNTs in 0.1 wt. \%, with ultrasonication for 1 hour and then kept undisturbed for 2 hours to settle out large aggregates, before uniformly dip coated onto the Si wafers. The samples were then heated at $250^{\circ} \mathrm{C}$ for several seconds to evaporate the solvent.

Atomic layer deposition of $\mathrm{Al}_{2} \mathrm{O}_{3}$ and $\mathrm{HfO}_{2}$ coatings on the MWCNTs was performed in a Cambridge Nanotech ${ }^{\circledast}$ Fiji System, in the thermal deposition mode with chamber reaction temperature of $250{ }^{\circ} \mathrm{C}$ and $200{ }^{\circ} \mathrm{C}$, respectively. The $\mathrm{Al}_{2} \mathrm{O}_{3}$ was produced with the precursor Trimethyl Aluminum (TMA) and thermal co-reactant $\mathrm{H}_{2} \mathrm{O}$, and the $\mathrm{HfO}_{2}$ was grown with Tetrakis (Dimethylamido) Hafnium $\left(\mathrm{Hf}\left(\mathrm{NMe}_{2}\right)_{4}\right)$ and $\mathrm{H}_{2} \mathrm{O}$. A series of deposition cycles (10, 30 and 50) were chosen to yield different coating thicknesses and uniformity, with a deposition rate of $\sim 1 \AA /$ cycle for both materials.

Both as-received and ALD coated MWCNTs were characterized on a WITec alpha $300 \mathrm{M}+$ Confocal Raman Microscope using a $532 \mathrm{~nm}$ laser. The Raman spectra were collected with 20X objective lens to obtain global statistic information, which were 
analyzed using commercial peak-fitting software (GRMS, Thermo Electron Corp., Philadelphia, PA). MWCNTs were ultrasonically taken off from the Si substrate in isopropanol and then dipped onto the TEM grids with holey carbon films for electron microscopy investigations. Both HRTEM imaging and STEM imaging with EDS analysis were performed with a JEOL - 2100F.

The MWCNTs were made into nanocomposite films using a polymer derived ceramic (PDC) based on a silicon alkoxide $\left(\mathrm{Si}(\mathrm{OR})_{4}\right)$ precursor with some OR sites substituted by hydride and vinyl groups. The PDC matrix was produced from this liquid PDC precursor by mixing of CSO-230 and CLC-PL005 platinum catalyst at a weight ratio of 100:1 (both from Extreme Environment Materials Solutions, LLC, Saratoga Springs, NY). The mixed liquid PDC precursor was diluted to $30 \mathrm{wt}$ \% in isopropanol and then infiltrated into the dispersed MWCNTs on the Si wafer using a spin coater to produce a dense and uniform nanocomposite film. The films were then cross-linked at $100^{\circ} \mathrm{C}$ for 30 min followed by pyrolysis which was performed in a tube furnace under continuous flow of a mixture of $95 \% \mathrm{Ar}$ and $5 \% \mathrm{H}_{2}$ with a flow rate of $100 \mathrm{~mL} / \mathrm{min}$. The temperature was first ramped up to $400^{\circ} \mathrm{C}$ at $10^{\circ} \mathrm{C} / \mathrm{min}$ and then to $1000^{\circ} \mathrm{C}$ at $1{ }^{\circ} \mathrm{C} / \mathrm{min}$, held at $1000^{\circ} \mathrm{C}$ for 1 hour followed by cooling down to $500^{\circ} \mathrm{C}$ in a controlled cooling rate of $1{ }^{\circ} \mathrm{C} / \mathrm{min}$ before being air cooled down to room temperature. After the heat treatment, a MWCNTs nanocomposite film was synthesized with an amorphous $\mathrm{Si}_{x} \mathrm{C}_{y} \mathrm{O}_{z}$ matrix. The films produced in this manner were $\sim 2 \mu \mathrm{m}$ thick. The CNT volume fractions are difficult to quantify precisely, but were estimated to be $20-30 \%$ based on SEM images and the relative amounts of material used to prepare the nanocomposites.

Thermal cracks developed in the MWCNT-PDC nanocomposite films, which may already occur even during the heating cycle when the polymer matrix undergoes the greatest shrinkage. This occurs because the stresses build up in the coatings due to both densification of the PDC and the thermal expansion mismatch between the coating and the Si substrates. These cracks made it possible to obtain basic information about the fracture characteristics of the nanocomposite films. SEM (LEO 1530 VP) was employed to observe the fracture surfaces. Cracked fragments of the nanocomposite 
films were also dispersed in isopropanol with ultrasonication and then dipped onto grids for TEM investigations.

Single tube pull-out tests were conducted to measure the interface shear strength (IFSS) between individual ALD coated CNTs and the PDC matrix. This approach has been reported in previous publications ${ }^{[20-22]}$. To summarize briefly, a thin layer of prepared PDC precursor was first dropped onto the sample shuttle of a customdesigned micromechanical device. An individual $\mathrm{HfO}_{2}$ coated CNT was then carefully loaded onto this previously prepared PDC layer, and several more drops of PDC were transferred onto the CNT to fully cover. The whole device together with embedded $\mathrm{CNT} / \mathrm{HfO}_{2}$ was put into a tube furnace (Lindbergh/Blue $\mathrm{M}^{\mathrm{TM}}$, Thermo Scientific) under continuous flow of a mixture of $95 \% \mathrm{~N}_{2}$ and $5 \% \mathrm{H}_{2}$ at $100 \mathrm{ml} / \mathrm{min}$. After heat treatment, Pt was deposited on the other end of $\mathrm{CNT} / \mathrm{HfO}_{2}$ in FEI Helios $660 \mathrm{SEM} / \mathrm{FIB}$ to firmly bond it to the other sample shuttle of the device. For the pull-out test, a quantitative Agilent nanoindenter with displacement resolution of $1 \mathrm{~nm}$ was employed to actuate the device and also to measure the load and displacement independently. The calibration of the loading device was well conducted and details can be referred to the previous publication $^{[23]}$. The complete pull-out test was recorded by a video to demonstrate the corresponding pull-out processes, and to ensure the test validity. After conducting this in-situ tensile test in the SEM, the device shuttles were intentionally broken and glued to a nickel grid with epoxy. Both morphology and composition of pulled out $\mathrm{CNT} / \mathrm{HfO}_{2}$ were then carefully reexamined by TEM (JEOL 2100 F) imaging and equipped Energy Dispersive Spectroscopy (EDS).

\section{Results \\ III.1 ALD Coatings on MWCNTS \\ The thickness of the ALD coatings was observed by TEM. For both the $\mathrm{Al}_{2} \mathrm{O}_{3}$ and $\mathrm{HfO}_{2}$ materials the deposition rate was $\sim 0.1 \mathrm{~nm}$ per cycle. In the X-ray energy spectra in Figure 1, Al and $\mathrm{Hf}$ are distinctly detected in the respective oxide coatings. The insets are}


the STEM bright field (BF) images which show that the $\mathrm{HfO}_{2}$ deposition creates a rougher surface than seen in the $\mathrm{Al}_{2} \mathrm{O}_{3}$ coatings.

Figure 2 presents TEM observations of original and ALD coated Helix and Mitsui MWCNTs. The lattice fringe images indicate that the Mitsui tubes have much better "quality" (graphitic nature) than the Helix tubes. The two types of MWCNTs also have contrastingly different morphology, where most Helix tubes are wavy while the Mitsui tubes are very straight. This difference is consistent with higher defect densities in the Helix tubes, which is confirmed in the Raman spectra that are shown in Figure 3(a). Here the $D$ and $G$ bands are generally attributed to defect and graphitic nature. By fitting each Raman spectrum, the integrated intensities for the $D$ and $G$ bands were extracted to obtain the $I_{D} / I_{G}$ ratios that are plotted in Figure $3(b)$.

The images in Fig. 2 for CNTs that were ALD coated for 10 cycles show that the surfaces are non-uniform for both $\mathrm{Al}_{2} \mathrm{O}_{3}$ and $\mathrm{HfO}_{2}$ cases, where clear variations in the coating material are indicated by red arrows. Non-uniformity was also observed after 30 cycles (not shown). After 50 cycles a more uniform and smooth $\sim 5 \mathrm{~nm}$ thick $\mathrm{Al}_{2} \mathrm{O}_{3}$ coating is created, while the $\mathrm{HfO}_{2}$ coating still remains discontinuous, but thicker compared to the 10 and 30 cycle materials. The Raman results in Fig. 3 indicate that the $\mathrm{Al}_{2} \mathrm{O}_{3}$ and $\mathrm{HfO}_{2}$ coated Helix tubes exhibit a small increase in the $\mathrm{I}_{\mathrm{D}} / \mathrm{I}_{\mathrm{G}}$ values, whereas no significant trend was observed for the coated Mitsui tubes.

\section{III.2 Pullout Behavior in PDC Nanocomposite Films}

The CNT dispersion in the PDC matrix was relatively uniform, as seen in the SEM micrograph in 4(a). In addition, extensive pull-out and crack bridging are seen in Figure 4(b). Representative SEM images of pulled out MWCNTs in PDC nanocomposites, including both original and ALD coated, are presented in Figure 5. With the same ALD coating conditions, the average pullout length for Mitsui MWCNTs is always larger than 
the corresponding Helix composites. Also the wavy and straight morphology for the Helix and Mitsui tubes respectively is still evident after pull out, with and without the ALD coatings.

The pullout lengths for the Helix and Mitsui tubes from the PDC matrix were measured and statistically analyzed. These results are plotted in Figure 6, as a function of the ALD coating thickness. A striking difference between the two types of MWCNTs is observed, where the pullout length of Helix tubes decreases with increasing coating thickness, while the reverse occurs with the Mitsui tubes. This occurred for both the $\mathrm{Al}_{2} \mathrm{O}_{3}$ and $\mathrm{HfO}_{2}$ coatings.

TEM investigations were also conducted to examine the MWCNTs after pull-out from the PDC matrix. Most of the Helix tubes had clean surfaces as seen in Fig. 7, with little evidence of either the ALD coatings or the PDC matrix adhered to the tubes. In contrast, pieces of the PDC matrix were still attached to the Mitsui tubes.

\section{III.3 Single tube pullout measurements}

In previous work, we reported single tube pull-out tests which measured interfacial bonding between the PDC matrix and Mitsui tubes that were uncoated ${ }^{[20]}$ or coated with ALD aluminum oxide ${ }^{[21]}$. Hafnia coatings are also relevant to the new work reported here, thus individual $\mathrm{CNT} / \mathrm{HfO}_{2}$ nanotubes with ALD coatings produced by 10 , 30 , and 50 cycles were investigated with the same type of test. Fig. 8a shows a 30-cycle $\mathrm{CNT} / \mathrm{HfO}_{2}$ with $97.2 \mathrm{~nm}$ diameter that was loaded onto a micromechanical device with well-controlled alignment under an optical microscope. The pulled out $\mathrm{CNT} / \mathrm{HfO}_{2}$ is shown in Fig. 8b. After the $\mathrm{CNT} / \mathrm{HfO}_{2}$ is pulled out, a clear cavity is left in the PDC matrix, which is circled in Fig. 8c.

The load-displacement curve obtained during the corresponding in situ measurement is shown in Fig. $8 \mathrm{~d}$. The observed step-wise features in the curve suggest that the interfacial bonding between $\mathrm{CNT} / \mathrm{HfO}_{2}$ and PDC fractures step by step due to the rough $\mathrm{CNT} / \mathrm{HfO}_{2}$ surface. The sudden load drop observed in Fig. $8 \mathrm{~d}$ indicates that the 
nanotube was abruptly pulled out. Assuming perfect interfacial bonding and uniform shear stress distribution, the corresponding maximum pullout force $\left(F_{\text {max }}\right)$ gives:

$$
\tau_{b}=\frac{F_{\max }}{\pi D l_{e m b}}
$$

where $\tau_{b}$ is the shear strength of the interface (IFSS), $D$ is the diameter of the $\mathrm{CNT} / \mathrm{HfO}_{2}$, and $l_{e m b}$ is its embedded length in the matrix. The IFSS of the $\mathrm{CNT} / \mathrm{HfO}_{2}$ that debonded from PDC in Fig. 8 is $25.3 \mathrm{MPa}$. Another three successful pull-out tests of $\mathrm{CNT} / \mathrm{HfO}_{2}$ with 30 ALD cycles were carried out and the average IFSS is $25.1 \pm 1.3 \mathrm{MPa}$, which is over 2.5 times higher than the average IFSS of pristine CNT debonded from PDC ${ }^{[20]}$. The surface roughness of $\mathrm{CNT} / \mathrm{HfO}_{2}$ with different ALD coating cycles varies considerably, as seen in Fig. 2. To reveal the relationship between the surface roughness and the IFSS, the $\mathrm{CNT} / \mathrm{HfO}_{2}$ with 10 and 50 ALD cycles were also embedded in and pulled out from PDC. Details of diameter and embedded length of $\mathrm{CNTs} / \mathrm{HfO}_{2}$, critical pull-out force, maximum normal stress, and corresponding IFSS are listed in Table 1. The average of IFSS between 30-cycle CNT/HfO 2 and PDC is higher than 20.9 \pm 2.6 , the IFSS between 10cycle $\mathrm{CNT} / \mathrm{HfO}_{2}$ and PDC. The 50 -cycle $\mathrm{CNT} / \mathrm{HfO}_{2}$ debonded from PDC possesses the highest IFSS, $28.9 \pm 2.6 \mathrm{MPa}$, which is more than three times higher than that pristine CNT debonded from PDC. Fig. 2 also shows that the surface roughness on the outer surface of the $\mathrm{CNT} / \mathrm{HfO}_{2}$ generally increases as the ALD cycles increase. Therefore, the improved IFSS is believed to result from strong mechanical interlocking between roughened hafnia surface and the PDC matrix.

Fig. 9 summarizes the IFSS of pristine CNT-PDC, $\left(\mathrm{CNT} / \mathrm{Al}_{2} \mathrm{O}_{3}\right)-\mathrm{PDC}$, and (CNT/ $\mathrm{HfO}_{2}-\mathrm{PDC}$ ). The pristine CNT-PDC holds the lowest interfacial shear strength due to its relatively smooth surface. Both $\mathrm{Al}_{2} \mathrm{O}_{3}$ and $\mathrm{HfO}_{2}$ coatings on CNTs increase the IFSS between CNTs and PDC, but the IFSS of CNT/ $\mathrm{HfO}_{2}-\mathrm{PDC}$ is much higher than that of (CNT/Al $\mathrm{O}_{3}$ )-PDC with same number of ALD cycles (after 50 ALD cycles $\mathrm{CNT} / \mathrm{Al}_{2} \mathrm{O}_{3}$ of 17.1 $\pm 1.2 \mathrm{MPa}$ is substantially lower than the corresponding $\mathrm{CNT} / \mathrm{HfO}_{2}$ value). The asfabricated $\mathrm{HfO}_{2}$ ALD coating on the CNTs is discontinuous compared to the $\mathrm{Al}_{2} \mathrm{O}_{3} \mathrm{ALD}$ coating in Fig. 2, thus the higher measured IFSS for the CNT/HfO 2 is consistent with the 
idea that surface roughness is a dominant factor here. These results indicate that the discontinuous coating can result in stronger mechanical interlocking with the PDC matrix during pull-out failure.

Characterization of the pulled out CNT/HfO 2 was conducted with TEM and STEM (similar analysis was previously reported for the $\mathrm{CNT} / \mathrm{Al}_{2} \mathrm{O}_{3}{ }^{[21]}$ ). The shuttle with the pulled out $\mathrm{CNT} / \mathrm{HfO}_{2}$ was intentionally broken and carefully glued onto a nickel grid. Fig. 10a shows an optical image. The sample area is over the hole, which guarantees that the $\mathrm{CNT} / \mathrm{HfO}_{2}$ can be successfully investigated in TEM. The pulled-out $\mathrm{CNT} / \mathrm{HfO} \mathrm{O}_{2}$ is barely seen under the optical microscope, but it can be easily observed with SEM (inset in Fig. 10a). Fig. 10b shows the STEM image of debonded $\mathrm{CNT} / \mathrm{HfO}_{2}$. It is difficult to identify the residues on $\mathrm{CNT} / \mathrm{HfO}_{2}$ after the pull-out test from this image only, however, the EDS result in Fig. 10c clearly shows strong hafnium and silicon peaks from the $\mathrm{HfO}_{2}$ and PDC, respectively. The silicon peak suggests there is strong interaction between $\mathrm{HfO}_{2}$ and PDC. This indicates that the rough surface of the $\mathrm{CNT} / \mathrm{HfO}_{2}$ allows the $\mathrm{HfO}_{2}$ islands and matrix to embed into each other and form strong interlocking during the pull-out, resulting in effective load transfer from the matrix to the $\mathrm{CNT} / \mathrm{HfO}_{2}$ and high IFSS values.

\section{Analysis and Discussions}

\section{IV.1 Impact of strength-limiting MWCNT defects}

As described in section III, all of the characterization methods employed indicate that the Mitsui MWCNTs have a significantly lower defect density. In general, increasing the density of strength-limiting defects will lead to shorter pull-out lengths, which is consistent with the comparison between the Helix and Mitsui CNTs. This type of behavior has been described with models of the relationships between fiber properties and the mechanical behavior of brittle matrix composites. For example, Curtin obtained the following relationship based on global load sharing and fiber strengths that are described with Weibull statistics ${ }^{[24,25]}$ : 


$$
\langle h\rangle=\frac{\lambda(m)}{4}\left[\frac{\sigma_{o} r L_{o}^{1 / m}}{\tau}\right]^{m /(m+1)}
$$

where $\langle h\rangle$ is the average pull-out length, $\sigma_{o}$ is the average fiber strength over a gauge length $L_{o}, \tau$ is the fiber-matrix interfacial sliding resistance, and $m$ is the Weibull modulus. The coefficient $\lambda$ depends only on $m$, and can be approximated with:

$$
\lambda(m) \cong \frac{0.664}{m^{0.6}}+0.716
$$

Based on the Weibull statistics invoked here, the average number of strength limiting defects at a stress $\sigma$, over a fiber length $L$ is given by:

$$
\phi=\frac{L}{L_{o}}\left(\frac{\sigma}{\sigma_{o}}\right)^{m}
$$

Thus for a fiber length of $L=L_{o}, \phi=1$ at a stress of $\sigma=\sigma_{o}$ (by definition). A larger number of $\phi$ for the same $\sigma$ and $L$ then implies a decrease in the characteristic strength $\sigma_{o}$ and/or a decrease in the gauge length (for a fixed value of $m$ ).

To evaluate our experimental observations, it is convenient to make a general comparison between two types of fibers, $j$ and $k$, where only the defect densities are different (i.e, $\tau$ is the same, and the distribution of defects is self-similar such that $m$ is the same). With this simplified model, the fiber with a higher defect density will exhibit a lower reference strength, $\sigma_{o}$, for a given value of $L_{o}$. This is also equivalent to setting the same $\sigma_{o}$ for both fibers, where $L_{o}$ decreases as the number of defects increases. Based on the latter, one can see that Eq. (4) leads to the following ratio of the gauge lengths for the two different types of fibers:

$$
\frac{L_{o, k}}{L_{o, j}}=\frac{\phi_{j}}{\phi_{k}}=\eta
$$

where $\eta$ is the ratio of the linear defect densities in the $j$ and $k$ fibers. Combining this with Eq. (2) then gives a ratio of average pull-out lengths:

$$
\frac{\langle h\rangle_{j}}{\langle h\rangle_{k}}=\left[\frac{1}{\eta}\right]^{1 /(m+1)}
$$


This approximate description shows that an increase in the number of strength limiting defects provides one likely explanation for the shorter pull-out lengths observed with the Helix tubes. However, based on Eq. (2) higher values of $\tau$ and lower values of $m$ can also reduce $\langle h\rangle$. More quantitative evaluation of pull-out lengths requires values for interface properties and failure statistics that are not available for these fibers. Some information can be inferred from the Raman $I_{D} / I_{G}$ ratio, where a simple semiquantitative interpretation has been used to estimate the average grain size in nanographites: ${ }^{[26,27]}$

$$
L_{a}=\left(2.4 \times 10^{-10}\right) \lambda_{\text {laser }}^{4}\left(\frac{I_{D}}{I_{G}}\right)^{-1} n m
$$

These materials differ from the CNTs used in our experiments, but it is interesting to note that the measured $I_{D} / I_{G}$ from Fig 4 and the wavelength employed $\left(\lambda_{\text {laser }}=532 \mathrm{~nm}\right)$ correspond to $L_{a}$ of $\sim 240$ and $\sim 1900 \mathrm{~nm}$ for the Helix and Mitsui MWCNTs, respectively. The larger $L_{a}$ value for the Mitsui CNTs corresponds to a volume of material which is comparable to one full nanotube, which is consistent with the idea that these materials have very low defect densities. In comparison, the much smaller $L_{a}$ value for the Helix tubes implies that these materials contain much higher defect levels. Based on this interpretation of the $I_{D} / I_{G}$ values, it appears that $\eta$ is on the order of 10 or higher. This is consistent with the experimental comparison between the pullout lengths. For example, with a value of $\eta=10$, Eq. (6) will match the measured $\langle h\rangle$ ratio for the uncoated tubes if $m=4.0$. Increasing $\eta$ to 100 gives the same $\langle h\rangle$ ratio if $m$ is increased to 9.1. For typical structural fibers, $2<m<20$, thus these comparisons demonstrate that physically reasonable $m$ and $\eta$ values are consistent with the observed pull out lengths.

\section{IV.2 Effect of ALD coatings on High Defect Density MWCNTS}

In conventional fiber-reinforced ceramic composites, interface coatings are often used to control the value of $\tau$. As described in section III.3, the single CNT pull-out measurements show that the ALD coatings increase the IFSS. This suggests an increase 
in $\tau$ as well, which is qualitatively consistent with $\mathrm{Eq} \mathrm{(2)} \mathrm{and} \mathrm{the} \mathrm{shorter} \mathrm{pull-out} \mathrm{lengths}$ for the ALD coated Helix tubes in Fig. 6. The observation that hafnia coatings lead to shorter pull-out lengths compared to the alumina also appears to be qualitatively consistent with the same logic (i.e., the higher measured IFSS values for the hafnia imply higher $\tau$ values in Eq. (2)). As noted in section III, possible reason for the higher IFSS values is that the $\mathrm{HfO}_{2}$ coatings are less uniform, resulting in a rougher surface.

The measured decrease in $\langle h\rangle$ as the coating thickness increases is also correlated with an increase in the measured IFSS values. Attributing this solely to changes in surface roughness is not consistent with the TEM, which shows somewhat smoother surfaces for thicker coatings. The observation that the thinner coatings do not fully coat the CNT surfaces suggests that weaker bonding to the carbon surfaces could explain the observed relationship between IFSS and coating thickness (i.e., if the PDC matrix bonds more strongly to the oxide coatings). However, to explain the observation that the ALD coatings on Helix tubes reduce the pull-out lengths by up to a factor of 3 with Eq. (2) would require a large increase in $\tau$. As noted above, a precise quantitative analysis with Eq. (2) is not possible for a number of reasons - global load sharing is known to be an oversimplification ${ }^{[25]}$ - also, the value of $m$ is not known here, and the measured IFSS values are not exactly the same as $\tau$ (as already discussed in section III). Most importantly, the reduced $\langle h\rangle$ values were only observed with the Helix tubes, whereas the IFSS measurements could only be performed with the Mitsui tubes. In spite of all of these issues, it is still interesting to note that evaluating the reduced pull-out lengths with the $5 \mathrm{~nm}$ thick hafnia coatings with Eq. (2) implies an increase in $\tau$ of roughly $300 \%$, which is comparable to the increase in the measured IFSS for the $5 \mathrm{~nm}$ thick hafnia coatings. This may be coincidental, since extending this comparison to the other thicknesses and to the $\mathrm{Al}_{2} \mathrm{O}_{3}$ coatings does not give the same quantitative agreement. For these cases, using the measured IFSS values for $\tau$ generally predicts pull-out lengths that are somewhat longer than those observed with the Helix tubes (although as noted above the observed trends are still in qualitative agreement with the measured $\langle h\rangle)$. 
The ALD coatings may also alter the CNTs to reduce $\langle h\rangle$ in other ways, beyond increasing $\tau$. For example, another possible explanation for the large decrease in the pull-out lengths is that ALD coatings can also decrease the fiber strength, $\sigma_{o}$, of the Helix MWCNTs. This would imply that the coatings increase the density of strength limiting flaws. This could occur if the defects inside of the ALD coatings can initiate fracture that propagates into the CNTs. Another possible effect is that the rougher surfaces of the coated nanotubes produce local stress concentrations that can activate defects inside of the CNTs at lower applied stress levels. The TEM images showing clean CNT surfaces after fracture suggest that this type of internal fracture may be prevalent in the Helix tubes (i.e., under the premise that the outer carbon layer then remains bonded to the oxide coating). This could occur if the ALD oxide layers enhance load transfer to the inner walls of the MWCNTs.

Based on the experimental results that are reported here, it is difficult to assess the processes that are discussed above in more detail. In addition to atomic scale defects, morphological factors are likely to play a role in the fracture process. For example, the pullout process with the Helix tubes will encounter a number of kinks, compared to the much straighter Mitsui tubes. It is difficult to determine how these kinks will impact pullout when the rigid oxide coatings are added to the tube surface. These kinks may alter local stress concentrations as proposed above, but further investigation of this type of phenomena is needed.

\section{IV.3 Effect of ALD coatings on Low Defect Density MWCNTS}

The most intriguing result in Figure 6 is that the Mitsui and Helix MWCNTs exhibit opposite trends. With the Mitsui tubes, the increase in $\langle h\rangle$ that occurs with increasing film thickness implies that these ALD coatings have a very different effect here. Two general approaches can be used to explain this observation, based on existing fracture models for fiber reinforced composites (i.e., Eq. 2, etc). First, if the coatings only alter the interface properties, then the increase in $\langle h\rangle$ implies a decrease in $\tau$. This requires that $\tau$ and the IFSS are moving in opposite directions (i.e., since the 
single tube measurements show that the ALD coatings increase the measured IFSS). This cannot be completely ruled out, if the IFSS is dominated by a high debond energy, with relatively low frictional sliding resistance $(\tau)$. If this is the case, then the opposite trends for the Helix tubes in Fig. 6 would still have to correspond to higher $\tau$ values (presumably because of their wavy surfaces).

A more likely possibility is that the coatings induce an increase in the fracture strength, $\sigma_{o}$, for the Mitsui tubes. This was not anticipated. One possibility is that strength limiting defects are concentrated at the MWCNT surfaces. With the low defect densities in these materials, eliminating failure at a small number of these surface sites could then lead to the observed longer pull-out lengths. The limited TEM evidence presented here provides evidence of strong bonding between the Mitsui CNTs and the ALD coatings, which implies that surface defects are relevant (i.e., because strong bonding is not expected to occur between these oxides and a perfect graphene surface). Another possibility is that interface effects enhance load transfer to the inner walls of the MWCNTs, which has been proposed by other researchers ${ }^{[28]}$. In section IV.2 we proposed that this could explain the enhanced internal fracture observed in the Helix tubes, where there are high defect concentrations. However, with the low defect density Mitsui tubes, enhanced load transfer to the inner walls should increase the effective fiber strength, $\sigma_{o}$, which is consistent with the experimental observations.

Overall, the comparisons between the Mitsui and Helix tubes demonstrate that variations in the MWCNT structure lead to substantial differences in the mechanical behavior of ceramic nanocomposites. The observations cannot be explained by merely viewing the ALD coatings as a method for varying the interfacial properties. It is instead more appropriate to view the coated MWCNTs as more complex core-shell structures, where both interface and effective bulk properties are altered by the ALD layers. The differences here are largely associated with phenomena that occur near the atomic scale (e.g., internal defects), but effects at larger lengths (e.g., fiber morphology) are also relevant. Disentangling these effects will require additional research. 


\section{Conclusions}

The experimental results reported here demonstrate that ultrathin coatings produced by ALD can be used to alter fracture processes in nanotube reinforced ceramics. The comparisons between two different types of MWCNTs indicate that coating interactions with the underlying reinforcement material are important. Here, the ALD coating creates core-shell structures which differ significantly from the uncoated CNTs. The ultrathin ALD layers here should not be viewed as just a means for controlling the interface properties of the fiberous reinforcements, although existing fracture models for fiber reinforced ceramics still provide a convenient basis for interpreting the measured pull-out behavior and the impact of the ALD coatings. In conventional composites, the fracture strength, $\sigma_{o}$, and Weibull modulus $(m)$ are normally treated as fiber properties, while $\tau$ is often viewed as an interface property that can be independently controlled with coatings and other surface treatments. In contrast to this, the results obtained with the two different MWCNTs used here indicate that complex interactions between the thin ALD coatings and the nanotubes can lead to intertwined effects at the nanoscale.

A more detailed analysis of fracture in CNT - PDC nanocomposites requires additional understanding of competing mechanisms in these materials. The fracture properties of both constituent phases are important. A more critical need is information about interfacial bonding and sliding for both the CNT/coating and coating/matrix interfaces. Also, the MWCNTs debonding processes in the nanocomposite bulk sample and the single CNT pullout tests can be different. Careful yet challenging experiments on making the two sets of experiments more comparable is required, from which a better understanding and correlation between the global statistical information and the nanoscale performance can be achieved. Valuable information about these behaviors can be obtained with additional nano-mechanical testing and computational modeling.

\section{Acknowledgements}


The authors gratefully acknowledge the financial support of this research by the US Department of Energy, Office of Basic Energy Sciences under Contract DE-FG0210 ER46771.

\section{References}

[1] J. J. Brennan, K. M. Prewo, Silicon-carbide fiber reinforced glass-ceramic matrix composites exhibiting high-strength and toughness, Journal of Materials Science 17 (1982) 2371-2383.

[2] D.B. Marshall. An Indentation Method for Measuring Matrix-Fiber Frictional Stresses in Ceramic Composites, Journal of the American Ceramic Society 67 (1984) C259-C-260.

[3] D.B. Marshall, B.N. Cox, A.G. Evans. The mechanics of matrix cracking in brittlematrix fiber composites, Acta Metallurgica 33 (1985) 2013-2021.

[4] D.B. Marshall, A.G. Evans. Failure mechanisms in ceramic-fiber ceramic-matrix composites, Journal of the American Ceramic Society 68 (1985) 225-231.

[5] B. Budiansky, J.W. Hutchinson, A.G. Evans. Matrix fracture in fiber-reinforced ceramics, Journal of the Mechanics and Physics of Solids 34 (1986) 167-189. 
[6] D.B. Marshall. Measurement of Interfacial Mechanical Properties in FiberReinforced Ceramic Composites, Journal of the American Ceramic Society 70 (1987) 542.

[7] C.H. Hsueh, M.K. Ferber, P.F. Becher. Stress-displacement relation of fiber for fiber-reinforced ceramic composites during (indentation) loading and unloading, Journal of Materials Research 4 (1989) 1529-1537.

[8] C.H. Hsueh, M.K. Ferber, A.A. Wereszczak. The relative residual fiber displacement after indentation loading and unloading of fiber-reinforced ceramic composites, Journal of Materials Science 28 (1993) 2227-2232.

[9] A.G. Evans, F.W. Zok. The physics and mechanics of fibre-reinforced brittle matrix composites, Journal of Materials Science 29 (1994) 3857-3896.

[10] Y.L. Wang, U. Anandakumar, R.N. Singh. Effect of fiber bridging stress on the fracture resistance of silicon-carbide-fiber/zircon composites, Journal of the American Ceramic Society 83 (2000) 1207-1214.

[11] G. Lin Hwang, K. Chu Hwang. Carbon nanotube reinforced ceramics, Journal of Materials Chemistry 11 (2001) 1722-1725.

[12] Z. Xia, L. Riester, W.A. Curtin, H. Li, B.W. Sheldon, J. Liang, B. Chang, J.M. Xu. Direct observation of toughening mechanisms in carbon nanotube ceramic matrix composites, Acta Materialia 52 (2004) 931-944.

[13] B.T.T. Chu, G. Tobias, C.G. Salzmann, B. Ballesteros, N. Grobert, R.I. Todd, M.L.H. Green. Fabrication of carbon-nanotube-reinforced glass-ceramic nanocomposites by ultrasonic in situ sol-gel processing, Journal of Materials Chemistry 18 (2008) 5344-5349. 
[14] A.J. Lopez, A. Rico, J. Rodriguez, J. Rams. Tough ceramic coatings: Carbon nanotube reinforced silica sol-gel, Applied Surface Science 256 (2010) 6375-6384.

[15] H.Z. Wang, X.D. Li, J. Ma, G.Y. Li, T.J. Hu. Multi-walled carbon nanotubereinforced silicon carbide fibers prepared by polymer-derived ceramic route, Composites Part a-Applied Science and Manufacturing 43 (2012) 317-324.

[16] J. Cho, A.R. Boccaccini, M.S.P. Shaffer. Ceramic matrix composites containing carbon nanotubes, Journal of Materials Science 44 (2009) 1934-1951.

[17] J. Cho, F. Inam, M.J. Reece, Z. Chlup, I. Dlouhy, M.S.P. Shaffer, A.R. Boccaccini. Carbon nanotubes: do they toughen brittle matrices?, Journal of Materials Science 46 (2011) 4770-4779.

[18] T.M. Besmann, B.W. Sheldon, R.A. Lowden, and D.P. Stinton. Vapor Phase Fabrication and Properties of Continuous-Filament Ceramic Composites, Science 253 (1991) 1104-1109.

[19] J.B. Davis, J.P.A. Löfvander, A.G. Evans, E. Bischoff, M.L. Emiliani. Fiber Coating Concepts for Brittle-Matrix Composites, Journal of the American Ceramic Society 76 (1993) 1249-1257.

[20] A. J. Kessman, J. Zhang, S. Vasudevan, J. Lou, B. W. Sheldon. Carbon Nanotube Pullout, Interfacial Properties, and Toughening in Ceramic Nanocomposites: Mechanistic Insights from Single Fiber Pullout Analysis, Advanced Materials Interfaces 2(2014) $14001101-10$. 
[21] Y. Yang, X. Liang, W. Chen, L. Cao, M. Li, B.W. Sheldon, J. Lou. Quantification and promotion of interfacial interactions between carbon nanotubes and polymer derived ceramics, Carbon 95 (2015) 964-971.

[22] Y. Ganesan, C. Peng, Y. Lu, P.E. Loya, P. Moloney, E. Barrera, B.I. Yakobson, J.M. Tour, R. Ballarini, J. Lou. Interface Toughness of Carbon Nanotube Reinforced Epoxy Composites, ACS Applied Materials \& Interfaces 3 (2011) 129-134.

[23] Y. Ganesan, Y. Lu, C. Peng, H. Lu, R. Ballarini, J. Lou. Development and Application of a Novel Microfabricated Device for the In Situ Tensile Testing of 1-D Nanomaterials, Journal of Microelectromechanical Systems 19 (2010) 675-682.

[24] W.A. Curtin. Theory of Mechanical Properties of Ceramic-Matrix Composites, Journal of the American Ceramic Society 74 (1991) 2837-2845.

[25] W.A. Curtin. Stochastic Damage Evolution and Failure in Fiber-Reinforced Composites. in: Erik van der G, Theodore YW, (Eds.). Advances in Applied Mechanics, vol. Volume 36. Elsevier, 1998. pp. 163-253.

[26] L.G. Cançado, K. Takai, T. Enoki, M. Endo, Y.A. Kim, H. Mizusaki, N.L. Speziali, A. Jorio, M.A. Pimenta. Measuring the degree of stacking order in graphite by Raman spectroscopy, Carbon 46 (2008) 272-275.

[27] M.S. Dresselhaus, A. Jorio, A.G. Souza, R. Saito. Defect characterization in graphene and carbon nanotubes using Raman spectroscopy, Philosophical Transactions of the Royal Society a-Mathematical Physical and Engineering Sciences 368 (2010) 53555377. 
[28] M. Estili, A. Kawasaki. Engineering Strong Intergraphene Shear Resistance in Multi-walled Carbon Nanotubes and Dramatic Tensile Improvements, Advanced Materials 22 (2010) 607-610. 
Figures:
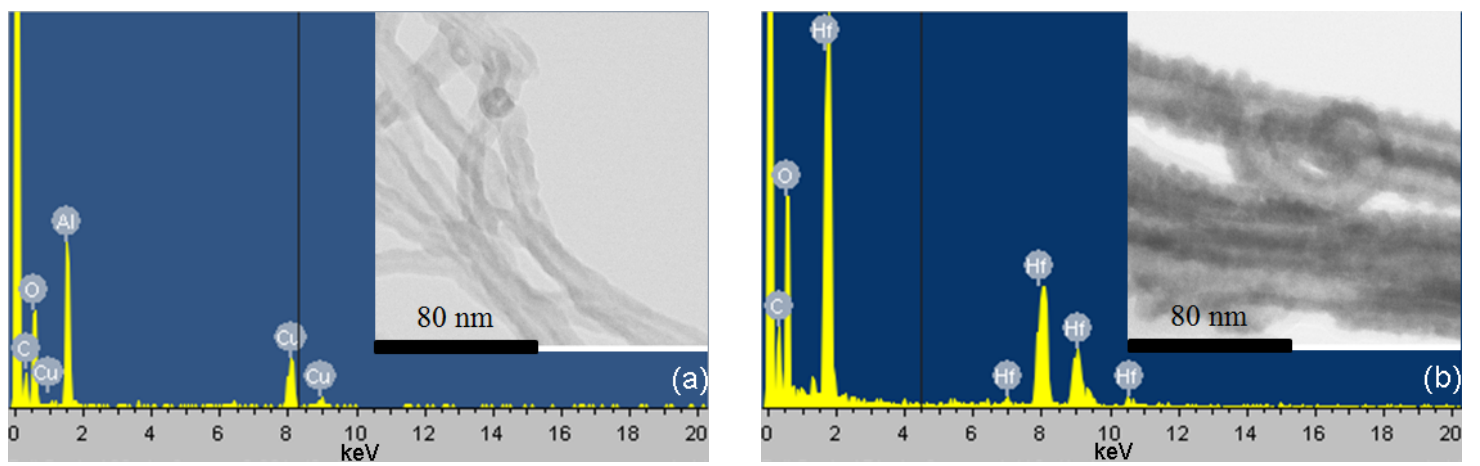

Figure 1: STEM EDS spectra of ALD coated MWCNTs. The inset in each spectrum is the STEM bright field image of the coated MWCNTs. (a) $\mathrm{Al}_{2} \mathrm{O}_{3}$ coating, 50 cycles at $250{ }^{\circ} \mathrm{C}$; (b) $\mathrm{HfO}_{2}$ coating, 50 cycles at $200^{\circ} \mathrm{C}$. 
Helix
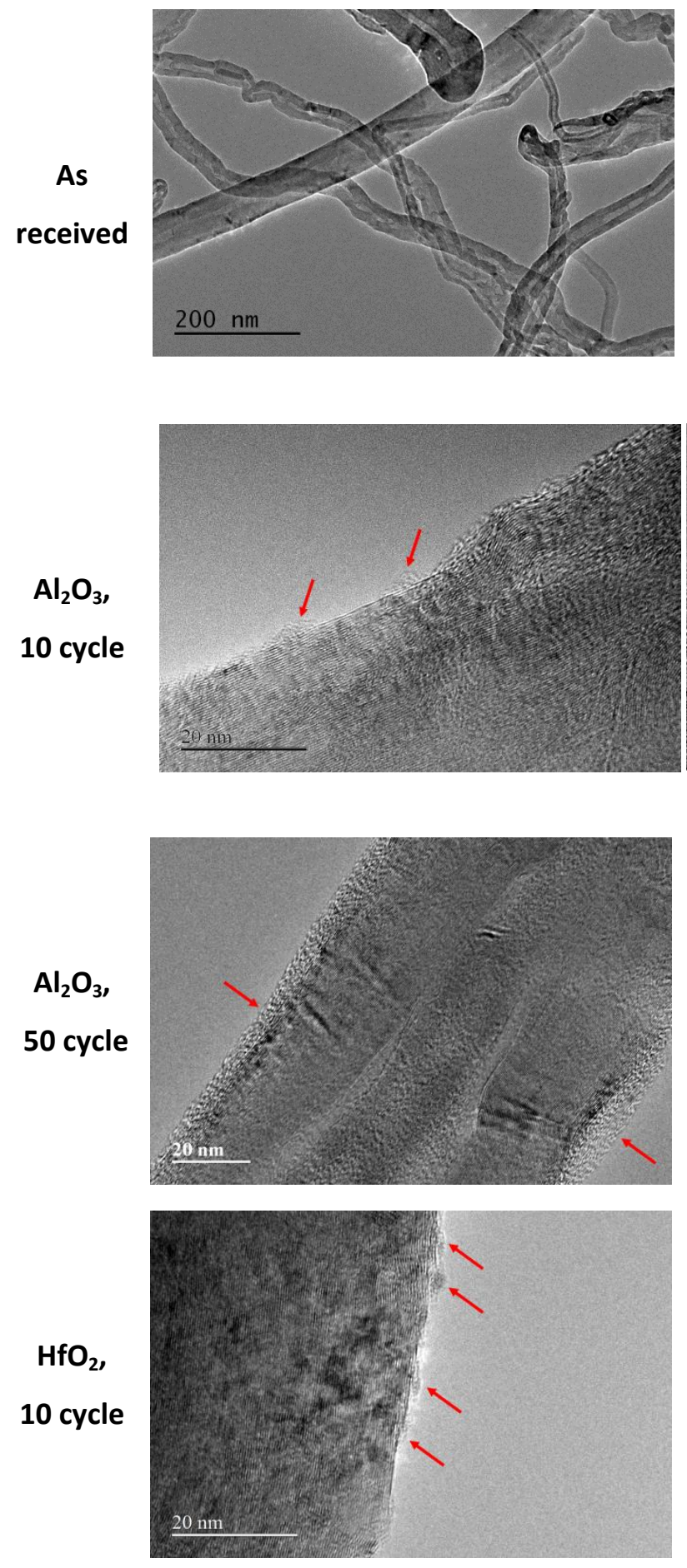

Mitsui
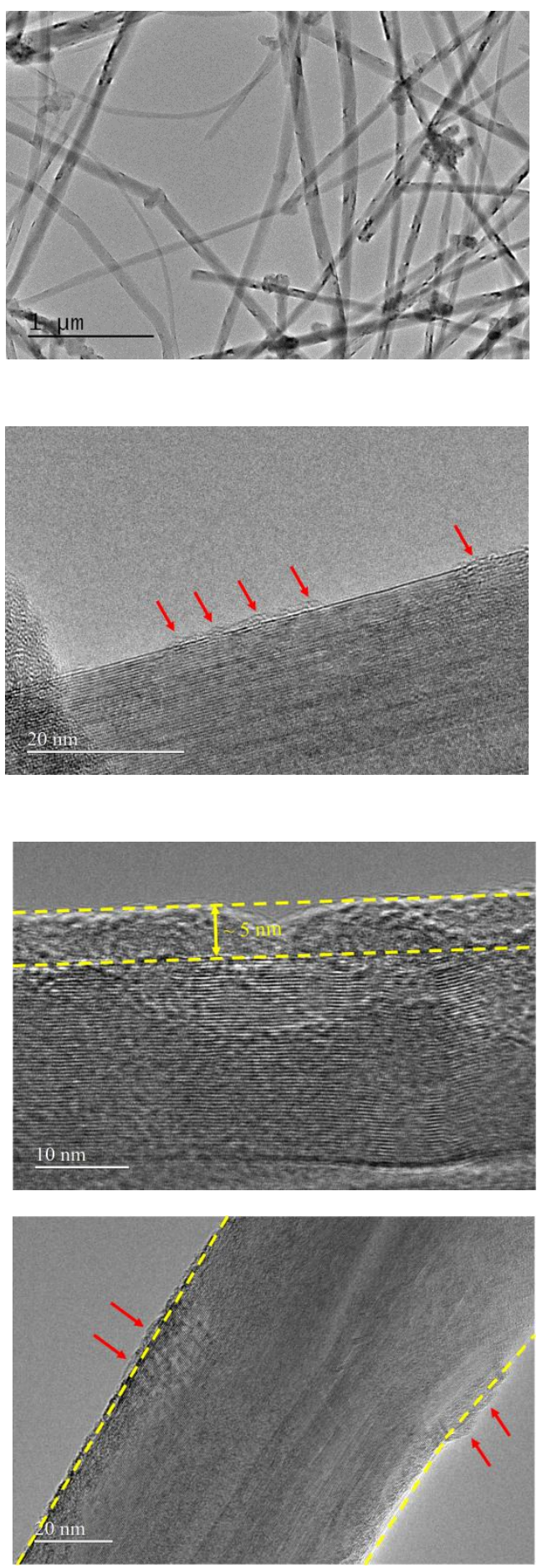

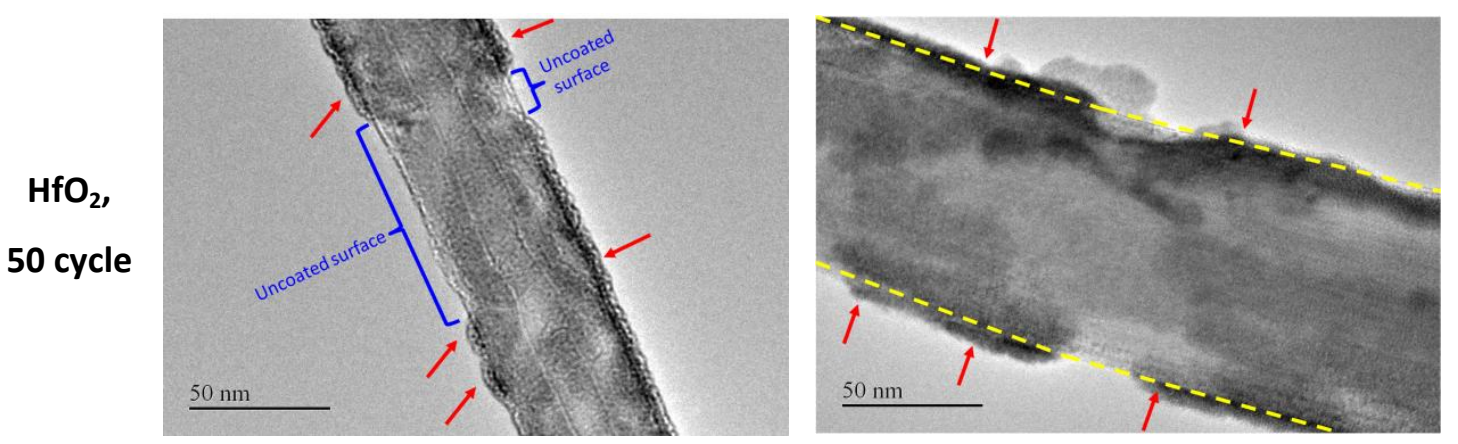

Figure 2: HRTEM images of original and ALD $\left(\mathrm{Al}_{2} \mathrm{O}_{3}, \mathrm{HfO}_{2}\right)$ coated Helix and Mitsui MWCNTs. In some images, red arrows were used to indicate the coating materials while yellow dashed lines delineate the coating from the surface of the MWCNTs. 
Helix
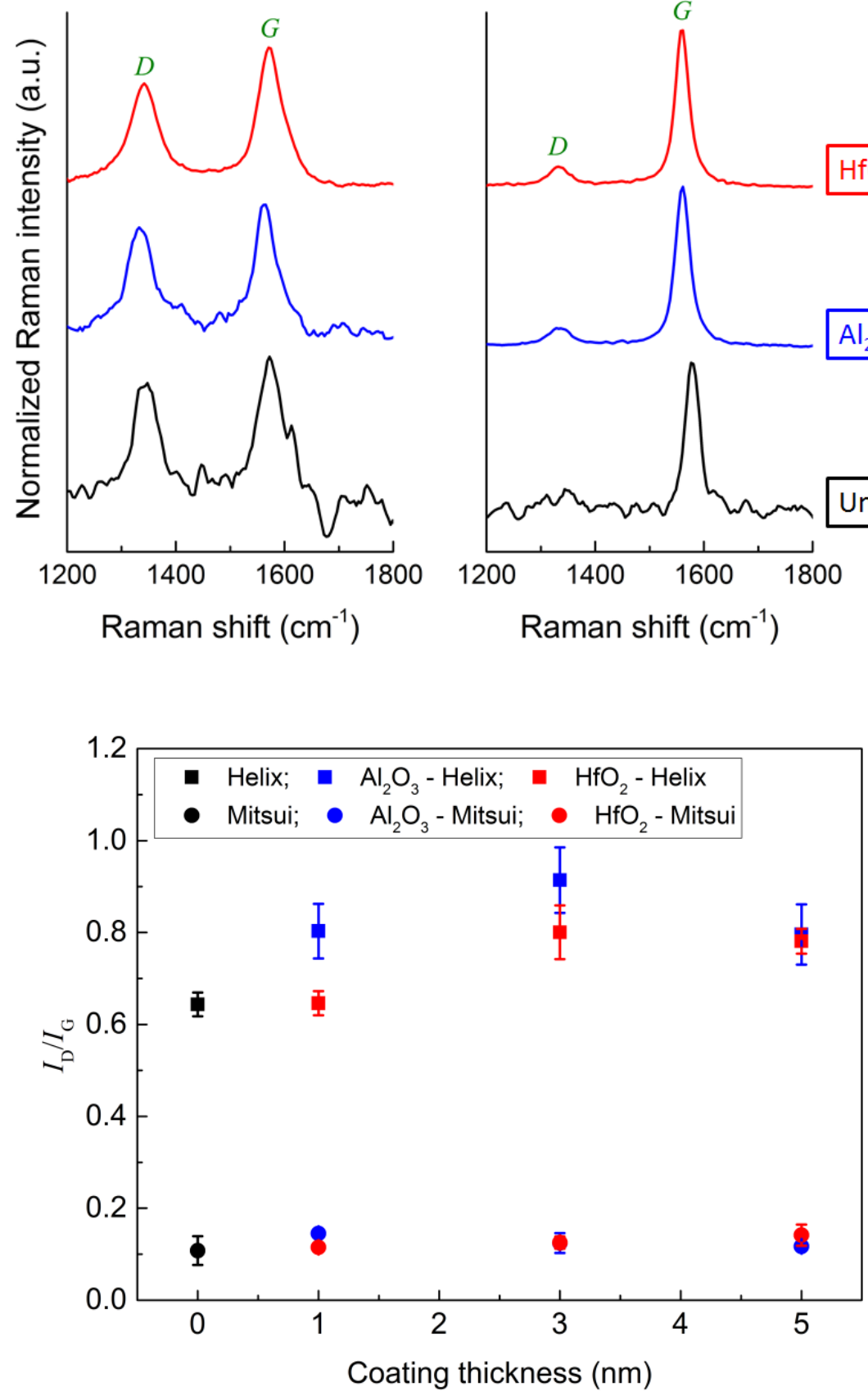

Figure 3. (a) Raman spectra of ALD coated Helix and Mitsui MWCNTs. The D and G bands are indicated, and the ALD deposition materials and cycles are shown on the right. (b) $I_{D} / I_{G}$ ratio obtained from Raman microspectroscopy analysis plotted versus ALD coating thickness. The filled square and round symbols represent Helix and Mitsui MWCNTs. 


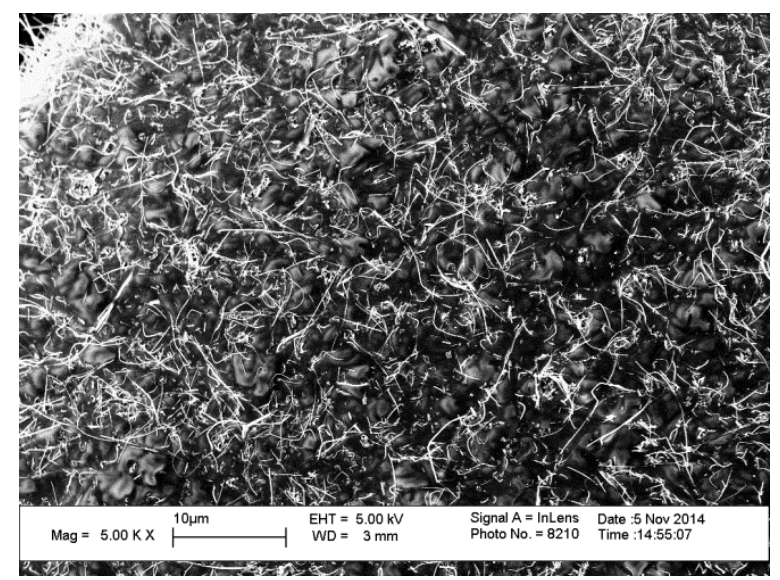

(a)

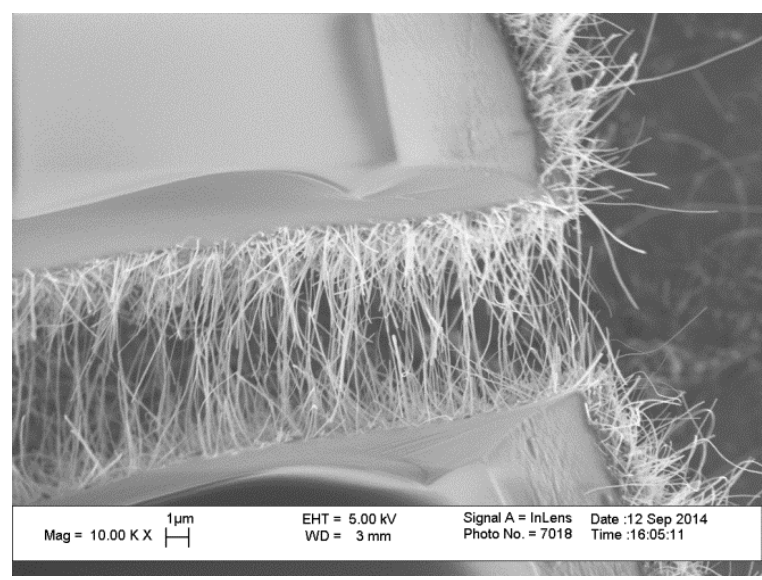

(b)

Figure 4: SEM images of ALD coated Mitsui MWCNT-PDC nanocomposite films. (a) Plane view showing the homogenous dispersion of 50-cycle $\mathrm{HfO}_{2}$ coated MWCNTs; (b) Pull-out and crack bridging observations with 50 -cycle $\mathrm{Al}_{2} \mathrm{O}_{3}$ coated MWCNTs. 
Helix
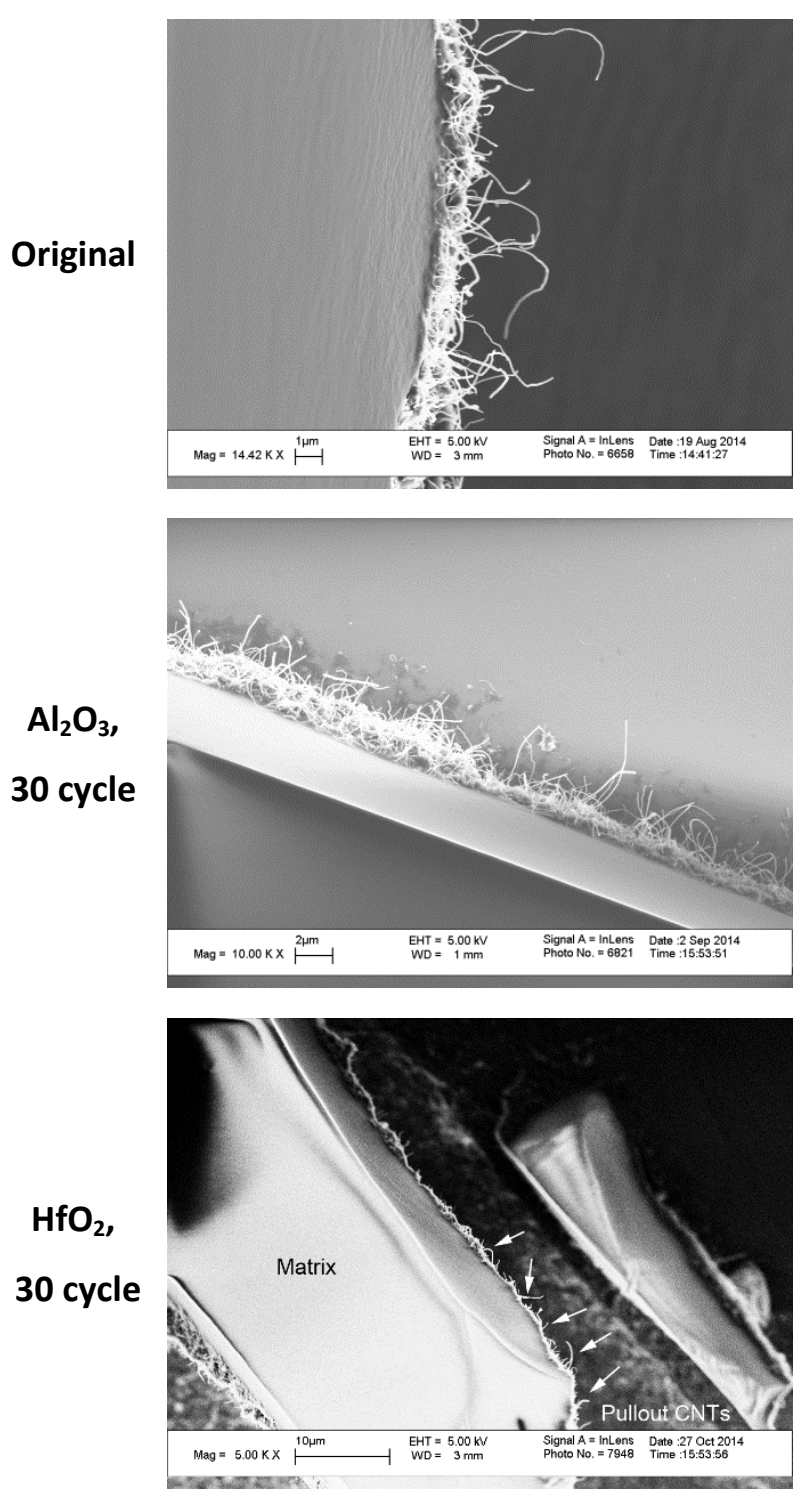

Mitsui
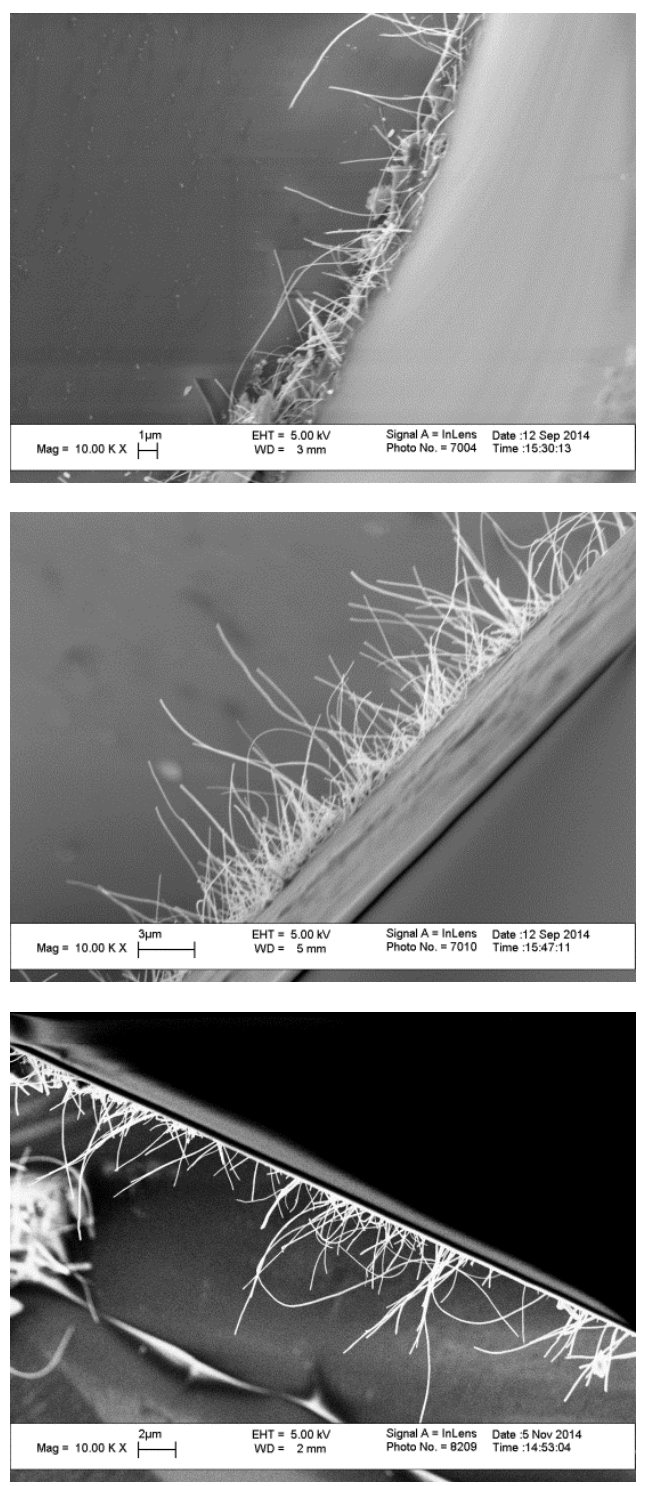

Figure 5: Representative SEM observations of original and $\mathrm{Al}_{2} \mathrm{O}_{3} / \mathrm{HfO}_{2}$ ALD coated MWCNTs pullout from PDC nanocomposite films. 


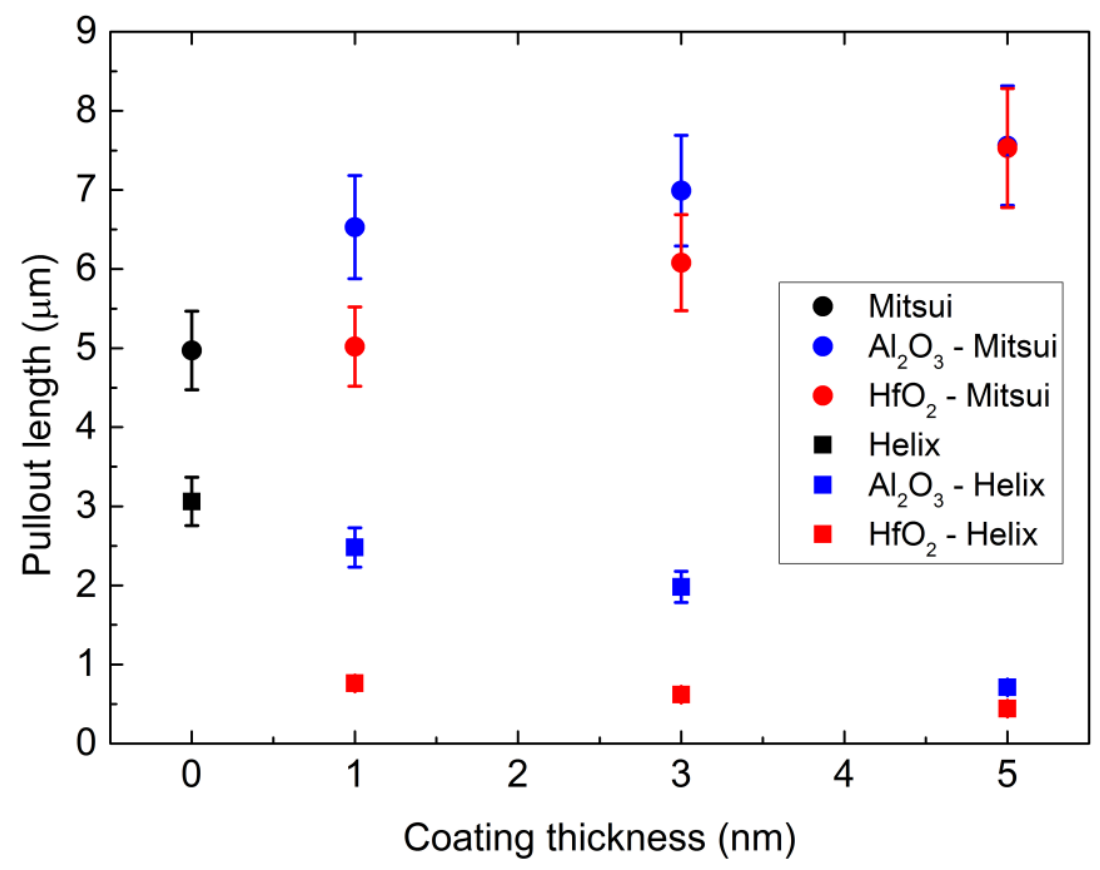

Figure 6: Pullout length of original and ALD coated MWCNTs plotted versus coating thickness. The filled square and round symbols represent Helix and Mitsui MWCNTs. 


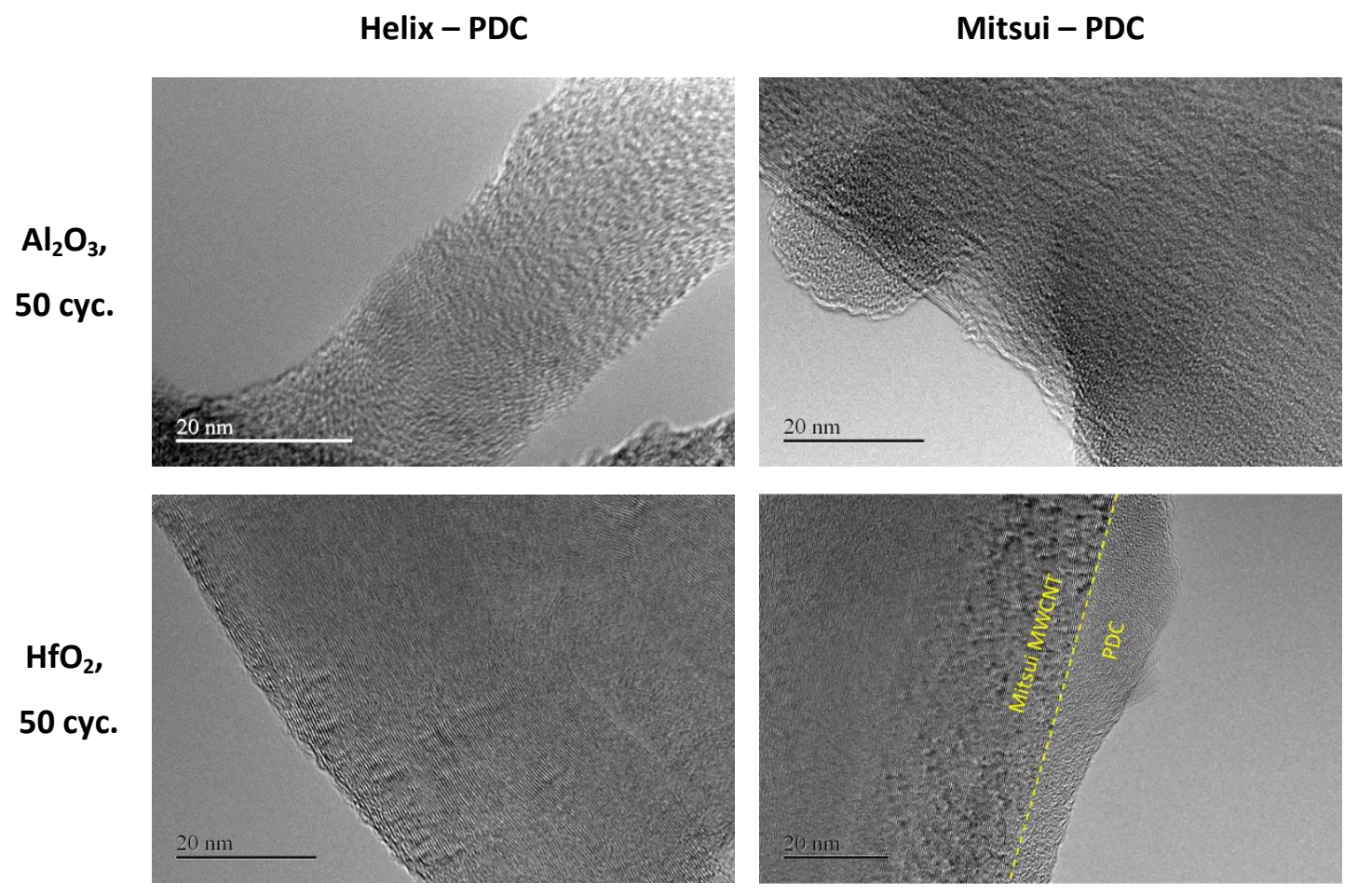

Figure 7: HRTEM observations of ALD coated MWCNTs after pull-out from the PDC nanocomposites: Helix (left column) and Mitsui (right column). The Helix surfaces were generally clean, while most of the Mitsui tubes have small PDC fragments attached to the surface. 

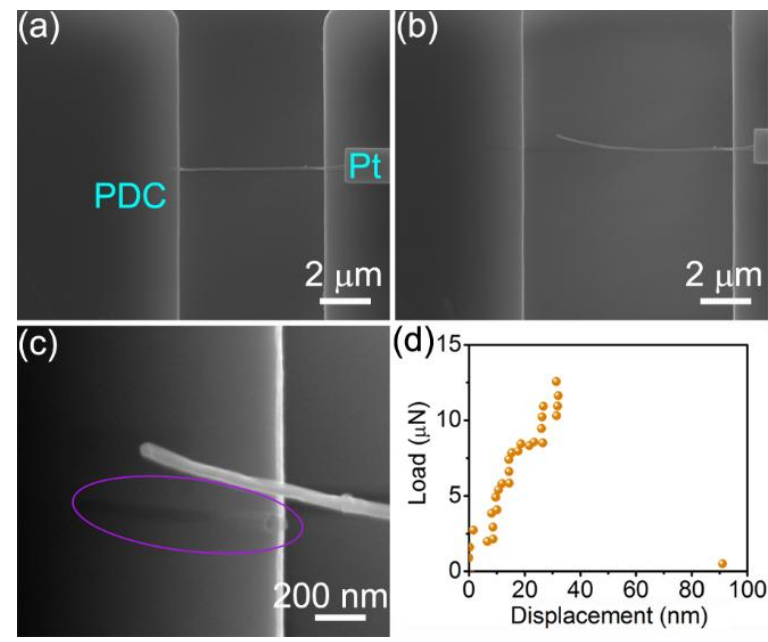

Figure 8. CNT/HfO 2 debonding from PDC. (a) and (b) SEM images of a CNT/HfO $\mathrm{HF}_{2}$ with diameter of $97 \mathrm{~nm}$ before and after debonding from PDC. (c) The left cavity in PDC. (d) Load-displacement curve of the $\mathrm{CNT} / \mathrm{HfO}_{2}$ debonding from PDC. 


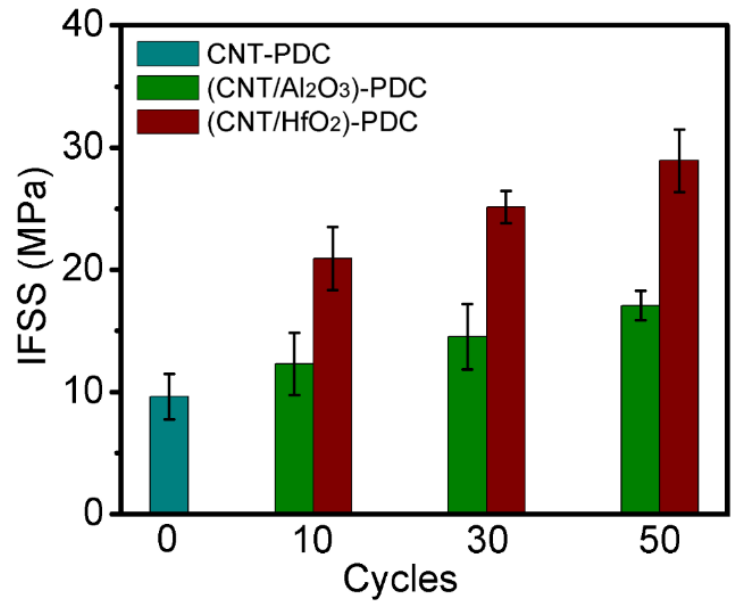

Figure 9. IFSS of pristine CNT-PDC, $\left(\mathrm{CNT} / \mathrm{Al}_{2} \mathrm{O}_{3}\right)-\mathrm{PDC}$, and (CNT/HfO $\left.{ }_{2}-\mathrm{PDC}\right)$. 


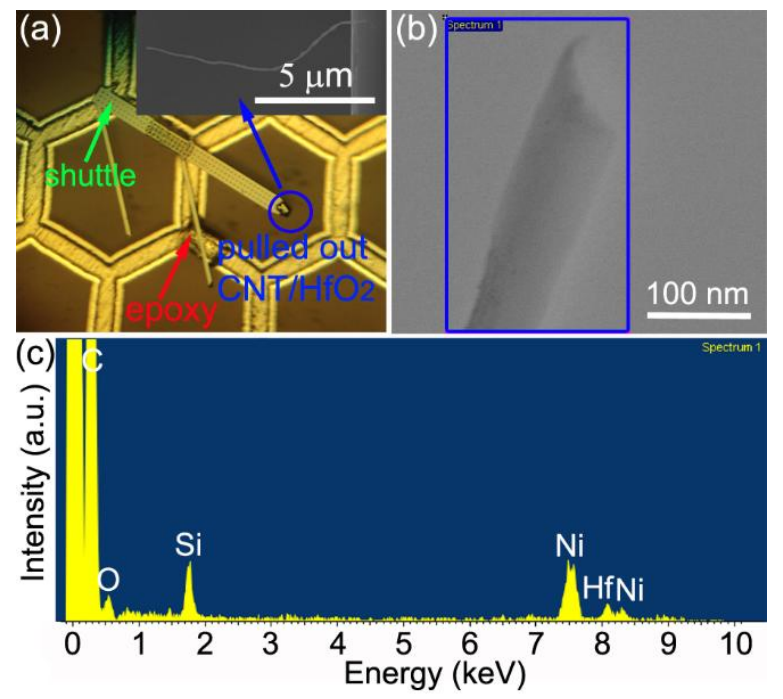

Figure 10. Post TEM analysis of the pulled-out $\mathrm{CNT} / \mathrm{HfO}_{2}$. (a) Optical image of pulled-out $\mathrm{CNT} / \mathrm{HfO}_{2}$ along with the shuttle of the micromechanical device. The inset in (a) is the SEM image of pulled-out CNT in (a). (b) STEM image of debonded CNT/HfO ${ }_{2}$. (c) EDS analysis of debonded $\mathrm{CNT} / \mathrm{HfO}_{2}$. 
Tables:

Table 1. Interfacial properties between $\mathrm{CNT} / \mathrm{HfO}_{2}$ and PDC.

\begin{tabular}{l|c|c|c|c|c|c}
\hline CNT/HfO 2 -PDC & $\begin{array}{c}\text { Embedded } \\
\text { depth } \\
(\mathrm{nm})\end{array}$ & $\begin{array}{c}\text { Nanotube } \\
\text { diameter } \\
(\mathrm{nm})\end{array}$ & $\begin{array}{c}\text { Critical } \\
\text { pullout force } \\
(\mathrm{mN})\end{array}$ & $\begin{array}{c}\text { Maximum } \\
\text { nominal stress } \\
(\mathrm{GPa})\end{array}$ & $\begin{array}{c}\text { IFSS } \\
(\mathrm{MPa})\end{array}$ & $\begin{array}{c}\text { Average } \\
\text { IFSS } \\
(\mathrm{MPa})\end{array}$ \\
\hline 10 cycles-01 & 3934.9 & 137.1 & 0.0352 & 2.39 & 20.78 & \\
10 cycles-02 & 2154.9 & 72.9 & 0.0088 & 2.11 & 17.81 & $20.9 \pm 2.6$ \\
10 cycles-03 & 3485.9 & 88.0 & 0.0175 & 2.88 & 18.17 & \\
10 cycles-04 & 3879.5 & 98.1 & 0.0292 & 3.86 & 24.41 & \\
\hline 30 cycles-01 & 1624.8 & 97.2 & 0.0126 & 1.77 & 25.34 & \\
30 cycles-02 & 1992.0 & 90.0 & 0.0148 & 2.32 & 24.74 & $25.1 \pm 1.3$ \\
30 cycles-03 & 4459.3 & 88.8 & 0.0330 & 5.43 & 23.65 & \\
30 cycles-04 & 1682.4 & 89.4 & 0.0134 & 2.13 & 26.81 & \\
\hline 50 cycles-01 & 1347.8 & 94.5 & 0.0114 & 1.62 & 28.46 & \\
50 cycles-02 & 1883.0 & 108.3 & 0.0196 & 2.13 & 30.58 & \\
50 cycles-03 & 1875.9 & 139.4 & 0.0237 & 1.55 & 28.89 & $28.9 \pm 2.6$ \\
50 cycles-04 & 4175.1 & 109.4 & 0.0413 & 4.39 & 25.02 & \\
50 cycles-05 & 2076.7 & 106.6 & 0.0248 & 2.78 & 31.74 & \\
\hline
\end{tabular}


Graphical Abstract

Graphical abstract
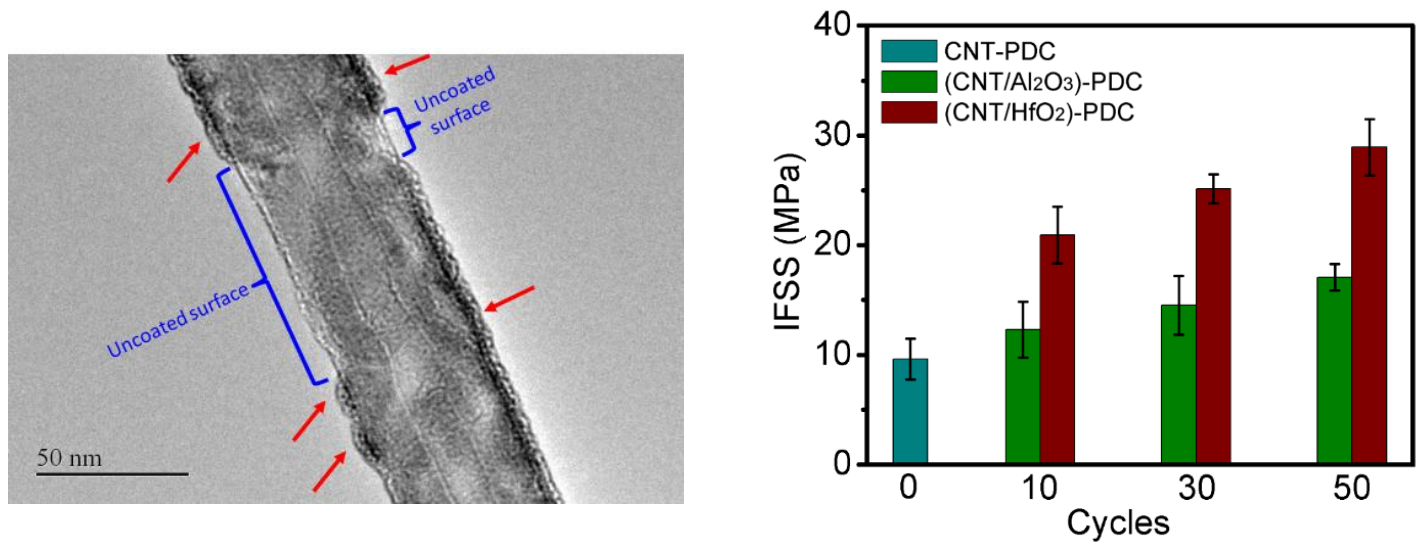

Fracture properties of core-shell nanotubes reinforced ceramic nanocomposites 